\title{
La crisis financiera
} internacional

Antonio Torrero Mañas 


\title{
INSTITUTO UNIVERSITARIO DE ANÁLISIS ECONÓMICO Y SOCIAL
}

\author{
DIRECTOR
}

Dr. D. Tomás Mancha Navarro

Catedrático de Economía Aplicada, Universidad de Alcalá

DIRECTOR FUNDADOR

Dr. D. Juan R. Cuadrado Roura

Catedrático de Economía Aplicada, Universidad de Alcalá

SUBDIRECTOR

\section{AREAS DE INVESTIGACIÓN}

ANÁLISIS TERRITORIAL Y URBANO

Dr. D. Rubén Garrido Yserte

Profesor Titular de Universidad

Universidad de Alcalá

ECONOMÍA AMBIENTAL

Dr. D. Diego Azqueta Oyarzun

Catedrático de Teoría Económica.

Universidad de Alcalá

ECONOMÍA LABORAL

Dr. D. Carlos Iglesias Fernández

Profesor Contratado Doctor

Universidad de Alcalá

ESTUDIOS SECTORIALES, FINANCIEROS Y PYME

Dr. D. Antonio García Tabuenca

Profesor Titular de Universidad

Universidad de Alcalá

SERVICIOS E INNOVACIÓN

Dr. D. Luis Rubalcaba Bermejo

Profesor Titular de Universidad

Universidad de Alcalá 


\section{DOCUMENTOS DE TRABAJO}

La serie Documentos de Trabajo que edita el Instituto Universitario de Análisis Económico y Social (SERVILAB), incluye avances y resultados de los trabajos de investigación realizados como parte de los programas y proyectos del Instituto y por colaboradores del mismo.

Los Documentos de Trabajo se encuentran disponibles en Internet http://www.iaes.es/iuaes sp/publicaciones.htm

\section{ISSN: $1139-6148$}

\section{LATEST WORKING PAPERS}

WP-01/08 THE COMPETITIVENESS OF EUROPEAN SERVICES

Luis Rubalcaba Bermejo, Gisela Di Meglio, Stefano Visintin, Andrés Maroto y Jorge Gallego

\section{WP-02/08 LABOUR PRODUCTIVITY AND CYCLICAL DYNAMICS IN THE SERVICE SECTOR \\ Andrés Maroto Sánchez}

WP-03/08 EXPANSIÓN DEL SECTOR PÚBLICO EMPRESARIAL EN LAS AUTONOMÍAS Y AYUNTAMIENTOS.EVOLUCIÓN Y ANÁLISIS DE LAS POSIBLES CAUSAS

Juan R. Cuadrado Roura y Marta Carrillo Neff

WP-04/08 STABILIZATION POLICIES IN ARGENTINA: AN ANALYSIS FROM THE PERSPECTIVE OF INFLATION UNCERTAINTY

Erica Fellinger Jusué y Tomás Mancha Navarro

WP-05/08 NEW WORK: OLD BARRIERS BUT NEW OPPORTUNITIES FOR WOMEN

Cecilia Castaño, Maria Caprile y Carlos Iglesias

WP-06/08 ENTREPRENEURSHIP, CREATIVE INDUSTRIES AND REGIONAL DYNAMICS IN SPAIN

Antonio García Tabuenca, Jose Luis Crespo Espert y Juan Ramón Cuadrado Roura

WP-07/08 INNOVATIVE AND CREATIVE ENTREPRENEURSHIP IN SPAIN

Juan Ramón Cuadrado Roura y Antonio García Tabuenca

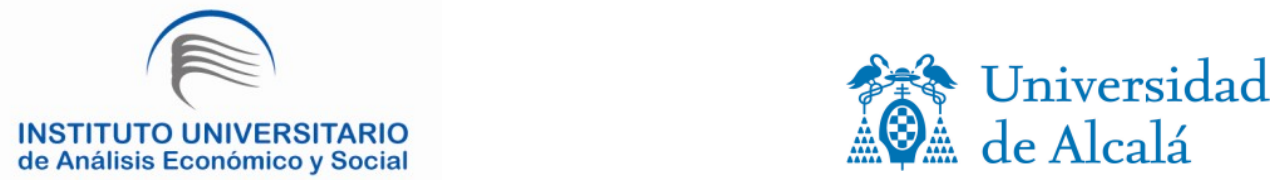

Plaza de la Victoria, 2. 28802. Alcalá de Henares. Madrid - Telf. (34)918855225

Fax (34)918855211 Email: iaes@iaes.es. WEB: www.iaes.es 


\section{LA CRISIS FINANCIERA INTERNACIONAL:}

\section{RESUMEN:}

La crisis financiera en la que estamos inmersos es una perturbación de importancia histórica. La alarma está siendo grande, las intervenciones públicas contundentes, y el coste de la crisis elevadísimo para el contribuyente. El lógico esperar que se intente reducir la excesiva propensión al riesgo de las finanzas actuales accionando tres palancas: 1) regulación y supervisión más estricta y extendida a todas las instituciones financieras 2) disminución de su capacidad de endeudamiento, y 3) desconfianza respecto a los posibles efectos desestabilizadores de la ingeniería financiera sofisticada.

\section{AUTORES:}

ANTONIO TORRERO MAÑAS. Catedrático de Estructura Económica. Universidad de Alcalá. 


\section{INDICE}

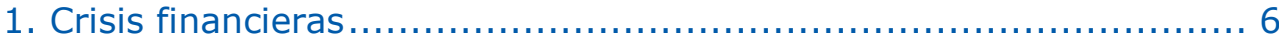

2. Intermediarios bancarios y Mercados financieros....................... 9

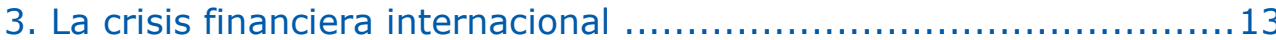

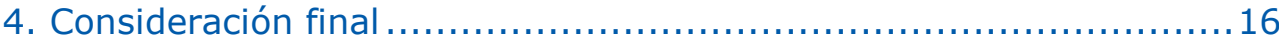




\section{CRISIS FINANCIERAS}

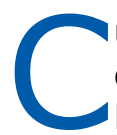

uando intentamos comprender un fenómeno tan complejo como la crisis financiera actual, la primera palabra que surge es modestia.

Modestia respecto del alcance de los conocimientos que tenemos los economistas para entender lo que está sucediendo; no digamos para aventurar lo que pueda acontecer

Una crisis financiera es un desorden agudo que altera el funcionamiento normal de los mercados, afecta de manera violenta a las valoraciones de los activos, y puede amenazar a la propia existencia de las instituciones financieras poniendo en peligro al conjunto del sistema económico.

¿Cuándo se produce una crisis financiera? No sabemos cuál puede ser el detonante que precipita el desorden y pone en marcha una reacción que puede ser acumulativa. Además, la razón precipitante de una crisis ilustra poco como orientación o aviso para prevenir otros episodios. Puede producirse el mismo acontecimiento en repetidas ocasiones, pero sólo si se dan determinadas condiciones se activa el proceso. Los detonantes son, por otra parte, muy variados: una caída de la bolsa, el alza en el precio de las materias primas, cambios en el ordenamiento legal, la quiebra inesperada de una gran empresa... y así podríamos seguir enumerando razones susceptibles de iniciar la crisis.

¿Cuáles son las consecuencias de una crisis financiera? Depende de cómo se trate el fenómeno y del éxito de las medidas que se adopten. El alcance del desorden inicial puede ser comparado con los efectos que tiene el desprendimiento de una piedra en una pendiente con numerosas rocas. Puede que no suceda nada, que se produzca un ligero desprendimiento y se detenga unos metros mas abajo, o que se provoque un alud.

No todo son brumas. Sabemos algunas cosas y en ellas tenemos que basarnos los economistas para intentar comprender un fenómeno tan complejo. Permítanme que en este primer punto aluda a cinco apoyos y advierta, inmediatamente después, sobre la escasa objetividad de la mayoría de los juicios que se emiten al respecto.

a. Desequilibrios acumulativos. Las crisis financieras suelen ser la consecuencia de desequilibrios que se van acumulando hasta llegar a ser insostenibles. El motivo al que se atribuye el inicio de la crisis actúa sobre una situación potencialmente inestable. Los mercados financieros son proclives a que los cambios sean violentos si el desequilibrio alcanzado es importante. Las valoraciones dependen de las expectativas de los rendimientos a largo plazo, que son susceptibles de cambios súbitos, cuya radicalidad desconcierta a los inversores y alienta su comportamiento gregario: el llamado efecto rebaño al que aludiré más adelante. 
b. A posteriori se advierte la lógica del proceso. A toro pasado, nos parece evidente la lógica del proceso y nos sorprendemos de no haber percibido antes la causa precipitante y el desarrollo de la crisis.

Pondré dos ejemplos de los excesos que pueden producirse:

En la burbuja de Japón que estalló en 1989, el valor inmobiliario atribuido al palacio imperial de Tokio superaba al total del Estado de California.

Durante la burbuja de las empresas tecnológicas de hace una década una empresa española: Terra, incluida en el apartado de tecnológicas, llegó a valer en el mercado más que Iberdrola, la gran empresa eléctrica española. Terra, hoy desaparecida del mercado, constituyó una gran decepción para miles de inversores, entre los que se encontraban entidades financieras de gran porte.

¿A quién no le parecen ahora disparatadas las valoraciones que se alcanzaron entonces? ¿No nos parece lógico ante la magnitud de los excesos, que se produjera una corrección violenta de las valoraciones?

c. Nadie controla el proceso de una crisis. Las crisis financieras se desencadenan de forma súbita y tanto su evolución como el desenlace no responden a un plan previsto y controlado. Las autoridades se ven obligadas a actuar bajo la presión de los mercados, en ocasiones sin información suficiente y en el cortísimo plazo.

d. Los Estados y Bancos Centrales intervienen en situaciones de crisis. Lo hacen para evitar el pánico en ahorradores e inversores y el colapso de mercados e instituciones financieras. Esta es una cuestión capital sobre la que hay que reflexionar. Los Estados y Bancos Centrales, en todos los países del mundo, ante una situación de crisis financiera importante, intervienen facilitando liquidez, salvando instituciones, bajando los tipos de interés e intentando por todos los medios que la parálisis y el desorden no afecten gravemente al sistema económico. Los economistas más liberales, particularmente los que piensan que los mercados financieros operan básicamente como los demás mercados, se muestran reticentes ante las intervenciones del Gobierno o de los Bancos Centrales en los mercados o con el salvamento de alguna institución bancaria importante. Se aducen dos razones en contra de las intervenciones.

La primera, es el riesgo moral (moral hazard). Esto es, la falta de disciplina que se traslada a los directivos de las empresas si ante las dificultades se organizan desde el sector público operaciones de salvamento. El efecto es el aumento de la propensión al riesgo puesto que los beneficios en tiempos de bonanza los reciben gestores y accionistas mientras que las pérdidas, en cambio, se socializan y corren 
a cargo del contribuyente. Hay que señalar, sin embargo, que muy a menudo los accionistas son perjudicados gravemente.

La segunda es el fomento de la inflación. Las intervenciones se centran en relajar las condiciones monetarias facilitando liquidez y bajando los tipos de interés para mejorar la valoración de los activos.

e. El efecto rebaño. En las crisis financieras el pánico es una característica esencial, lo cual implica reacciones emocionales y comportamientos gregarios. Permítaseme que dedique un breve espacio a éste asunto. Hay muchos que piensan que actuar imitando la conducta de los demás demuestra la irracionalidad de los mercados, como esos pequeños roedores del Norte de Europa (lemmings) que periódicamente se suicidan en manada despeñándose por un acantilado. No tengo esa opinión. Observar el comportamiento de los demás y emular sus pautas es perfectamente racional. Lo es por dos motivos: de orden social y de orden lógico. Me referiré a ellos inspirándome en el pensamiento de Keynes que dejó reflexiones memorables al respecto.

En cuanto al orden social, la colectividad considera más negativamente los errores en solitario que los cometidos por la mayoría de los que intervienen en los mercados. Con un punto de ironía me atrevería a decir que la colectividad aprecia más al que se equivoca con la mayoría que al acertante en soledad.

Respecto al orden lógico, en situaciones de incertidumbre radical, cuando no es posible fundamentar nuestras decisiones utilizando probabilidades, indicios de conocimiento, o atisbos de racionalidad, pero no hay más remedio que decidir, tendemos a suponer que quizás los demás están mejor informados. En la gran mayoría de los casos eso no es cierto, pero nos sirve de justificante y calma nuestros nervios. Piénsese por ejemplo en una estimación del precio del cobre dentro de treinta años (ejemplo propuesto por Keynes). La cantidad de variables es tal, que realizar con fundamentos racionales y verosímiles una estimación es harto difícil (a mí me parece imposible), pero la vida económica exige decidir en condiciones de incertidumbre. En esas circunstancias imitar el comportamiento de otros resulta plenamente comprensible.

Expuestos los 5 apoyos, terminaré este primer apartado con la advertencia que titularé: el sombrero del analista.

Mis alumnos saben lo pesado que me pongo con este asunto. Como nuestro conocimiento de las crisis es tan precario, surge -como he dicho- la reacción natural de pensar que los demás saben más, lo cual puede ser cierto, y tendemos a apreciar los análisis de los responsables políticos o de los altos cargos de la Administración a los que suponemos más preparados e informados. No entraré en si efectivamente disponen de mayor información y tienen mejor preparación; afirmo, sin embargo, 
que sus manifestaciones están sesgadas por su propia responsabilidad institucional.

El ministro de economía o el responsable de un banco central dice, no lo que piensa, sino lo que puede decir de acuerdo con el puesto que ocupa. ¿Se imaginan ustedes al Gobernador de un Banco Central advirtiendo de la vulnerabilidad de una institución sobre la que ejerce vigilancia? ¿Creen ustedes que el Ministro de Economía no asegurará que la divisa de su país es firme aunque tenga sobre la mesa un documento alarmante sobre la situación de la moneda en los mercados?

Ese comportamiento entra en el sueldo y está muy bien que sea así; también está muy bien que el economista tenga conciencia de ello y matice los análisis con la responsabilidad, o los intereses, del que los formula. En síntesis, sabemos poco, pero debemos desconfiar de los análisis de los que aparentemente saben más. No podemos renunciar a nuestro propio juicio pese a lo limitado de nuestra información o capacitación. No debemos abdicar de tener nuestra propia opinión.

\section{INTERMEDIARIOS BANCARIOS Y MERCADOS FINANCIEROS}

E $\mathrm{n}$ las tres últimas décadas se han producido alteraciones fundamentales del marco institucional de los sistemas financieros. Haré referencia a las dos más importantes: 1) los Mercados Financieros (monetarios, bursátiles y de productos derivados) tienen una importancia cada vez mayor, 2) Se han difuminado las fronteras que antes separaban con bastante nitidez el ámbito de actuación de las diferentes instituciones financieras.

Las razones de esos cambios y las consecuencias de los mismos no es posible examinarlos ahora con detalle, pero me parece interesante aludir muy brevemente a los efectos sobre la velocidad del ajuste y respecto a la distribución del riesgo.

Los intermediarios bancarios son, por su propia naturaleza, suavizadores del ciclo puesto que una parte fundamental de sus activos no están sometidos a las valoraciones continuas de los mercados -caso de los créditos- ni están obligados a contabilizar de forma instantánea otros activos (inmuebles, acciones) según las cotizaciones diarias de los mercados. Como todo, esta capacidad de mantener plusvalías y minusvalías en sus libros sin que afloren de forma continua produciendo pérdidas o beneficios contables, tiene ventajas e inconvenientes. El principal inconveniente es la posibilidad de acumular resultados negativos que pueden alcanzar un volumen extraordinario, poniendo en peligro la existencia de la propia institución, al sistema financiero y afectando a la calidad en la asignación de los recursos. 
El caso más claro y cercano en el tiempo ha sido la crisis bancaria japonesa que se produjo en la década de los noventa, después del estallido de la burbuja bursátil-inmobiliaria en 1989. La banca nipona, fuertemente comprometida con la dinámica alcista de los mercados, resultó muy afectada por la caída de las valoraciones que reducía las garantías (acciones e inmuebles) de su cartera de créditos, y por la dificultad de reestructurarla, debido a los compromisos implícitos consecuencia de la relación estable con sus clientes. El resultado fue que no se afrontó con decisión el cambio de situación: se continuó financiando a empresas con problemas y sin futuro, impidiendo la asignación de los recursos a actividades más prometedoras. Lo prolongado del ajuste de la economía japonesa se debe, en buena medida, a estas circunstancias.

No hay duda de que si la financiación empresarial de las empresas japonesas hubiera dependido más de los mercados financieros y menos de los intermediarios bancarios, el reconocimiento de los problemas empresariales se hubiera detectado con mayor prontitud, reduciéndose la financiación a las empresas con dificultades y reasignando los recursos hacia actividades con mayor futuro.

Siguiendo con el caso japonés, el embalsamiento de los problemas en las entidades bancarias supuso una acusada concentración del riesgo en sus balances, lo cual provocó una crisis del propio sistema bancario que precisó de ayuda pública y sufrió un costoso y dilatado proceso de saneamiento. Nada de esto se hubiera producido con esa intensidad si los mercados hubieran tenido un mayor protagonismo. Los mercados hacen posible el reconocimiento inmediato de las situaciones problemáticas $\mathrm{y}$, además, permiten una mayor diversificación del riesgo entre numerosos inversores (individuos, empresas e instituciones de inversión colectiva) que muestran, mediante la selección de sus inversiones la mayor o menor tolerancia al riesgo, y las actividades que estiman más prometedoras.

Tanto si se trata de intermediarios bancarios como de mercados financieros, en el caso de una crisis financiera, las autoridades intentarán moderar los aspectos más negativos. Las fórmulas de intervención son, no obstante, diferentes en bancos y mercados puesto que también son distintas las reacciones y las decisiones que adoptan los inversores en los mercados y los directivos de las entidades bancarias. En el caso de crisis en los mercados, ya no se trata de una relación entre el Gobierno y un número limitado de presidentes de bancos, sino de la capacidad de los administradores públicos para influir en el estado de ánimo de un colectivo de millones de inversores.

Como consecuencia del mayor protagonismo de los mercados, los desequilibrios financieros son ya menos susceptibles de negociación y control; ahora, la efectividad de las medidas para combatir las crisis financieras depende de la credibilidad que les otorguen los mercados tanto a las medidas como a las autoridades que las proponen. 
La segunda alteración fundamental a la que he hecho referencia es a lo difuso de las fronteras que antes separaban con bastante nitidez el ámbito de actuación de las diferentes instituciones financieras.

Hace tres décadas podía considerarse, a efectos de las crisis financieras, que existía un núcleo duro en los sistemas financieros: la actividad de la banca comercial o relacional, y otro más volátil en torno a los mercados. La simbiosis entre bancos y mercados se ha ido acentuando; los bancos realizan actividades cada vez más ligadas a los mercados, y las instituciones que operan en éstos dependen, asimismo, de la financiación y de la prestación de los servicios específicamente bancarios.

Antes, la estabilidad del sistema financiero requería, sobre todo, el cuidado y vigilancia del núcleo duro, pero ahora la interrelación entre todas las instituciones impone la necesidad de que la regulación, la vigilancia y la supervisión se extienda a todas las instituciones financieras, puesto que existe una malla densísima de operaciones entre ellas.

El caso de la crisis del LTCM (Long Term Capital Management), en 1998, nos dio un primer aviso. Vimos como la Reserva Federal se preocupó y propició una solución negociada para evitar la quiebra de un hedge-fund. ¿Qué hacia un Banco Central ocupado en la suerte de un hedge-fund dirigido por supersofisticados gestores, dedicado al manejo de grandes fortunas $\mathrm{y}$, por tanto, sin estar estrechamente regulado ni supervisado? Pues simplemente velar por la estabilidad del sistema financiero americano. Si el LTCM no hubiera podido hacer frente a sus compromisos, su caída hubiera afectado gravemente a los que tenían contrapartidas con el fondo, y sobre todo a los financiadores, lo cual hubiera puesto en peligro la estabilidad económica del mundo.

Los financiadores-salvadores del LTCM dan una idea de las interrelaciones que se han creado entre las instituciones financieras. Estaban todos los grandes bancos de inversión norteamericanos, también bancos comerciales de esa nacionalidad así como dos bancos universales suizos, uno alemán, otro inglés y dos franceses. En total 14 entidades.

Estas instituciones habían financiado al LTCM... y además trataban de imitar sus operaciones operando con un grado de apalancamiento similar al del LTCM. Un apalancamiento de 1 a 25 en la proporción de recursos propios y ajenos significa que la pérdida del $4 \%$ en el valor de los activos provoca la quiebra. Esa proporción era ampliamente sobrepasada por el LTCM... y por muchos de sus salvadores, sobre todo por los bancos de inversión.

Las instituciones financieras actualmente protagonistas de los mercados: los hedge-funds, las firmas de capital riesgo... aparecen fuertemente conectadas con los bancos de inversión y con las instituciones de inversión colectiva (fondos de inversión y de pensiones). Sus 
operaciones están ligadas también con los bancos puramente comerciales. Todas dependen marcadamente de la situación y de la liquidez de los mercados financieros. Por eso se comprende la tendencia a centralizar la regulación y la supervisión de todas las instituciones financieras; se entiende también la presión para que se haga más intensa la regulación de los hedge-funds, puesto que su posible inestabilidad afectaría no sólo a los mercados sino al sistema bancario y al conjunto de las instituciones financieras.

A la interrelación, la complejidad y al protagonismo creciente de los mercados hay que añadir la nota de la internacionalización. Una característica esencial de las finanzas es la extraordinaria movilidad de los recursos financieros que se trasladan de manera prácticamente instantánea. De hecho, estamos ya en un único mercado financiero de carácter global, pero que se regula por autoridades nacionales. Por eso, en la crisis actual, se ha impuesto la colaboración entre los principales bancos centrales para llevar a cabo una actuación coordinada.

Pese a que se han difuminado las fronteras que antes separaban a las diferentes instituciones financieras, y aunque todas ellas sean más dependientes de los mercados financieros, siguen existiendo diferencias importantes. Permítanme que distinga entre los bancos comerciales puros y los bancos de inversión; esta distinción me servirá más adelante para matizar las contundentes intervenciones públicas que son en estos días primera noticia de los informativos de todo el mundo. Para facilitar la comprensión, piensen ustedes en dos actividades: en la agricultura y en la caza.

Los bancos comerciales son, digámoslo así, bancos dedicados a actividades como las agrícolas, esto es, de tipo recurrente, con un plazo dilatado entre la siembra y la recolección, y con preocupación por el seguimiento del cultivo, esto es, de la relación con la clientela concebida a largo plazo. Los bancos de inversión se dedican a la caza, a la búsqueda de piezas, de operaciones concretas que les permitan un ingreso inmediato y en ocasiones importantísimo si la pieza que derriban es de gran tamaño.

Esa banca de inversión, captadora de los mejores talentos universitarios, acostumbrada a una competencia feroz para captar y cerrar operaciones, ha sido la protagonista de la revolución financiera de los últimos treinta años. Esa aristocracia de las finanzas ha promovido la innovación financiera, y sus ejecutivos tenían ingresos millonarios en plena juventud, eran los master del universo como los denominó Tom Wolfe en su genial libro "La hoguera de las vanidades".

Han sido todo eso... y algo más: han sido los principales responsables de la escalada en la propensión al riesgo en todo el mundo.

De manera que el aumento de la propensión al riesgo no proviene sólo ni a mi juicio principalmente- de las intervenciones de las autoridades. Las engendra el propio sistema financiero, que no responde al diseño de 
nadie sino que es la consecuencia de la liberalización y de la presión competitiva. En el actual sistema financiero, el estímulo hacia la innovación financiera y la fortísima competencia, hace que la dinámica gire en torno a una docena de entidades (sobre todo Bancos de Inversión y Universales) que operan a nivel mundial. Estos han sido los auténticos responsables del aumento de la propensión al riesgo en todos los mercados y también los responsables de la crisis financiera mundial.

En esta dinámica, el tiempo afecta al prestigio y a los beneficios obtenidos por los directivos de las empresas y de las instituciones financieras. En las fases de auge, cuando se engendran los desequilibrios que finalizarán abruptamente después, éstos protagonistas son grandes visionarios que merecen recompensas y alabanzas. Después de la crisis, cuando se hace inventario, ésos mismos héroes pasan a ser sospechosos de fraude y manipulación.

\section{LA CRISIS FINANCIERA INTERNACIONAL}

\footnotetext{
- I origen de la crisis procede de la fuerte expansión del crédito - hipotecario en los Estados Unidos, en un entorno de tipos de interés reducidos en términos nominales y negativos en términos reales.
}

La expansión del crédito hipotecario requería un aumento de la demanda lo cual implicaba relajar las condiciones de los préstamos, concediéndolos a personas de dudosa reputación financiera, pero dispuestas a aceptar -por eso mismo- un tipo de interés más elevado que hacia extraordinariamente rentable estas operaciones. Todo descansaba en la confianza de que el continuo aumento del precio de las viviendas garantizaba el buen fin de los créditos concedidos.

Se puso en marcha, así, una rueda que pronto adquirió velocidad considerable proporcionando beneficios extraordinarios a bancos e instituciones financieras que participaban en éste círculo nada virtuoso. Para alimentarlo hacían falta recursos y aquí entra la innovación financiera; una de las más fructíferas sería la titulización.

La titulización consiste en la venta de los créditos por parte de los concesionarios incorporándolos a instrumentos financieros, los cuales se venden a inversores particulares e institucionales (fondos de pensiones, por ejemplo) deseosos de obtener una rentabilidad mayor que la de otros títulos de renta fija (deuda pública, por ejemplo).

Se había descubierto la forma de aumentar la velocidad de la rueda. Las entidades concesionarias de los créditos hipotecarios podían sacar éstos de su balance sin consumir recursos propios. Si las autoridades reguladoras hubieran puesto límites a estas prácticas o hubieran exigido la provisión de los recursos propios aunque los créditos hipotecarios 
concedidos se sacaran del balance, el límite del invento hubiera sido la disponibilidad del capital propio de los intermediarios bancarios. Sólo el Banco de España tomó éste tipo de precauciones entre los bancos centrales y, por eso, entre otras cosas, España ha sido uno de los pocos países europeos no infectados directamente por las hipotecas de alto riesgo (subprime), que han tenido, sin embargo, un fuerte impacto en otros países europeos.

La rentabilidad de los instrumentos creados nutridos con los préstamos hipotecarios se acentuaba con un alto grado de endeudamiento, el cual se obtenía de los mercados financieros internacionales, que confiaban en la garantía implícita de las conocidas entidades promotoras de los instrumentos (los bancos de inversión de forma destacada). Por otra parte, la demanda de los inversores requería la legitimación de la calificación otorgada por las sociedades de "rating". La calificación más alta era concedida a paquetes de títulos que contenían una combinación de hipotecas de primera calidad junto a otras dudosas. La calificación máxima habilitaba a instituciones de inversión colectiva y otros compradores institucionales a incorporarlos en las carteras.

Por este procedimiento se consiguió el milagro de que familias de Ohio o Iowa, sin empleo y de reputación financiera dudosa, pudieran comprar su vivienda financiada por un fondo de pensiones de Japón, Australia o Europa .

¿Qué sucedía si las dudas sobre la reputación crediticia se hacían realidad o si se reducía la valoración de las viviendas financiadas? En ese caso, el montaje se venía abajo como un castillo de naipes. Los instrumentos de titulización veían reducidos sus ingresos lo cual disminuía la rentabilidad prevista decepcionando a los inversores finales e incrementando sus deseos de vender las participaciones compradas. Los mercados financieros y los intermediarios bancarios dudarían de las gestoras de los créditos hipotecarios muy apalancadas recortando la financiación. El mecanismo se frenaba. ¿Qué les sucedería a los bancos concesionarios de las hipotecas? ¿Habían transferido el riesgo realmente? Mientras todo marchaba bien, el riesgo y la gestión estaban transferidos a los instrumentos que ellos mismos habían promocionado. Sin embargo, cuando estos instrumentos tuvieron pérdidas, los bancos se vieron obligados a incluir de nuevo en sus balances los créditos que antes habían sacado y a asumir los resultados negativos, ampliando su capital y alarmando a los mercados.

¿Cuál era la valoración real de los créditos hipotecarios? ¿Cuánto valían las participaciones de los instrumentos de titulización con préstamos hipotecarios de distinta calidad? Nadie lo sabe. No hay mercados organizados que los valoren sino estimaciones que toman como fundamento el único apoyo posible: los datos del pasado.

Se instaló la inseguridad en los mercados financieros, pero la asunción de pérdidas cuantiosísimas de los bancos que concedieron originalmente las hipotecas, llevó a la desconfianza en el mercado interbancario. Los 
partícipes en éste sensible y delicado mercado no se fiaban unos de otros. Desapareció la liquidez y con ello disminuyo la capacidad de financiación del sistema bancario.

Había llegado la hora de la intervención de los Gobiernos y de los Bancos Centrales, y su mayor preocupación era restaurar el normal funcionamiento de los mercados, en particular, el mercado interbancario.

Dedicaré un minuto a la catarata de sucesos que se están produciendo desde el pasado día 15 de Septiembre que en el futuro se considerará una fecha histórica. Ese día las autoridades de los Estados Unidos permitieron la quiebra de Lehman Brothers, el cuarto banco de inversión más importante de ese país. A partir de esa insólita decisión, se acentúa, de forma aparentemente paradójica, el intervencionismo del Gobierno en el sistema financiero: inyección masiva de recursos en una gran empresa de seguros (AIG); integración de Merrill Linch en un gran banco comercial; y creación de una institución que comprará créditos dudosos con dinero público para sanear los balances de entidades bancarias privadas. ¿Qué ha pasado?

Tardaremos meses en conocer los detalles de las negociaciones y de la incidencia del factor humano en estas decisiones. Es licito, sin embargo, aventurar algunas razones. La primera, la gravedad de la situación; ante una debacle de esta magnitud las autoridades no han dudado en intervenir en los mercados; la segunda, que se ha dejado quebrar a un gran banco de inversión y las autoridades han inducido a los otros a que se sitúen al amparo de algún gran banco comercial.

\section{¿Qué lectura tiene este comportamiento de la Administración?}

No crean ustedes que hay un plan preconcebido de actuación. Como antes he señalado, las autoridades han ido, y van, a remolque de los acontecimientos y se ven obligadas a reaccionar en el cortísimo plazo. Teniendo esto en cuenta lo que parece es que se intenta desmontar o reducir protagonismo de los bancos de inversión a los que se atribuye la responsabilidad del aumento del riesgo y del desorden financiero mundial.

Parece que, ante los excesos y la inestabilidad que han generado los bancos de inversión, el protagonismo en el próximo futuro, será de los bancos comerciales, más pausados, más aburridos, más agricultores, sin tanta arrogancia y prepotencia como los bancos de inversión. Este es el gran cambio de orientación que me ha parecido advertir en las intervenciones masivas que se están adoptando estos días. El tiempo dirá si esta apreciación es correcta.

Permítanme que vuelva al comienzo de esta conferencia cuando resaltaba la lógica de los procesos... a posteriori: ¿Era razonable pensar en la continuidad indefinida de un mecanismo consistente en financiar a prestatarios dudosos fiados en la continua revalorización de la vivienda? 
Lo que ha sucedido es que se estaban aceptando por todos los agentes niveles crecientes de riesgo, espoleados por la fuerte presión competitiva para poder obtener una cuota mayor de este invento magnífico.

Cada crisis financiera tiene sus propias particularidades y constituye un episodio singular, con el denominador común de que se relajan las apreciaciones del riesgo que se asume. Merece la pena subrayar dos aspectos de la crisis actual:

a. La crisis financiera actual se ha centrado en países desarrollados con finanzas sofisticadas. No ha afectado -hasta ahora al menosa los países emergentes. No solo eso. Son los recursos de éstos países emergentes (exportadores de petróleo, China y Rusia principalmente) los que están cubriendo la recapitalización de los bancos más afectados por la crisis. No deja de llamar la atención que la banca suiza, presumiblemente una de las más conservadoras del mundo, haya sido la más afectada por este vendaval.

b. Los grandes protagonistas de este desorden son un pequeño grupo de entidades capaces de captar cantidades extraordinarias de recursos de los mercados, del sistema bancario y de las instituciones de inversión colectiva sin que los reguladores tengan idea del riesgo que están asumiendo y de quien lo está financiando.

\section{CONSIDERACIÓN FINAL}

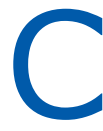

omo sucede siempre que se produce una gran crisis financiera surgen voces que proponen modificaciones del marco institucional para evitar que se produzcan los mismos excesos. Eso sucedió en la Gran Depresión promoviéndose el New Deal, que suponía una reforma radical destinada a compartimentar el ámbito de las instituciones financieras, a reducir la competencia entre instituciones y, en definitiva, a disminuir la propensión al riesgo y aumentar la seguridad de los ahorradores.

Ahora también se reclaman reformas institucionales en la misma dirección y las protestas son especialmente fuertes en Europa. No faltan argumentos para la indignación y el escándalo.

El boom constructor de viviendas en los Estados Unidos, impulsado por innovaciones ideadas por entidades norteamericanas, ha sido financiado por todo el mundo hacía el que han exportado activos financieros de calidad dudosa, respaldados por las tres agencias de calificación más importantes, todas también americanas. El resultado ha sido una 
convulsión mundial que ha afectado al crecimiento de todos los países, no sólo de los Estados Unidos, donde -al fin y al cabo- se han construido las viviendas que han originado el problema.

Sin embargo, Europa también ha participado en la fiesta. Importantes bancos europeos, siguiendo la estela de las finanzas americanas, funcionan ya con un carácter global y han distribuido los productos de alto riesgo conformados por las hipotecas de baja calidad.

Como antes he señalado, sabemos algunas cosas, sobre todo que los Gobiernos adoptarán políticas activas para tratar de restablecer la normalidad en los mercados. No obstante, ignoramos muchas otras: ¿Cuál es la auténtica dimensión del problema? ¿Cuánto tiempo puede prolongarse la inestabilidad? ¿Cuáles serán los efectos sobre el crecimiento económico, el empleo y la inflación de esta crisis financiera? No lo sabemos.

La mayor frecuencia de las perturbaciones financieras de las últimas décadas aparece ligada al aumento de la propensión al riesgo derivada de una durísima competencia y a un ritmo de innovaciones financieras extraordinario. Ésto, junto al predominio de los mercados que implica revisiones constantes de las cotizaciones y fuertes alteraciones de las valoraciones, hace de las finanzas un terreno potencialmente muy inestable.

El principal ejercicio de las finanzas es ahora predecir el comportamiento de los mercados; el apoyo básico para desvelar ese misterio es como se comportaron los mercados en el pasado ante situaciones similares. En torno a este asunto se ha avanzado en la modelización del comportamiento de los mercados y en la medición del riesgo de manera prodigiosa, dedicándose a ello ingentes recursos humanos y económicos. Las crisis financieras ponen de relieve, sin embargo, que las previsiones más sofisticadas fallan a veces de forma estrepitosa puesto que, a posteriori, se demuestra que no se habían incluido en el modelo variables que la realidad ha mostrado que eran relevantes.

Recurrir al comportamiento del pasado para intentar desvelar cómo será el futuro, es un recurso obligado, pero es preciso tener conciencia de las limitaciones que ello implica. Cierto que algunas pautas se repiten, pero en otras ocasiones no es así puesto que intervienen variables que no existían en el pasado. Además, los datos estadísticos no pueden incorporar el estado de ánimo existente cuando se produjo la información lo cual le resta utilidad para reflejar situaciones con un diferente clima de opinión.

Ante esta evidencia caben dos posturas: insistir en el perfeccionamiento de los modelos de previsión confiando en que su progresiva complejidad permita afinar las predicciones; o aceptar que existen zonas de incertidumbre radical en el comportamiento de algunas variables. En éste segundo caso, se es menos optimista respecto a la posibilidad de conocimiento del futuro $y$, por tanto, en cuanto a la capacidad de 
medición del riesgo. Creo que mi posición de desconfianza se trasluce de ésta exposición y la he expuesto con detalle en mis dos últimos libros *.

Lo que está sucediendo en estos días, será objeto de análisis detallados en el futuro. La alarma está siendo grande, las intervenciones públicas contundentes, y el coste de la crisis para el contribuyente elevadísimo. Es lógico esperar que se intente reducir la excesiva propensión al riesgo de las finanzas actuales actuando sobre tres palancas: 1) regulación y supervisión más estricta y extendida a todas las instituciones financieras; 2) disminución de su capacidad de endeudamiento, y 3) desconfianza respecto a los posibles efectos desestabilizadores de la ingeniería financiera sofisticada.

* Torrero, A. (2006). Crisis financieras. Enseñanzas de cinco episodios. Ed. Marcial Pons. Madrid.

Torrero A. (2008). Revolución en las Finanzas. Represión y Liberalización Financiera. Ed. Marcial Pons. Madrid. 


\section{AUTOR}

\section{Antonio Torrero Mañas}

Comienza su carrera profesional en MAPFRE Mutualidad de Seguros donde ocupó cargos directivos en sociedades de inversión. Ha sido Consejero Delegado de AGECO (Asesoramiento y Gestión Económica), Presidente del Banco Hipotecario de España, Presidente de Reit S.A., Consejero del Instituto Nacional de Hidrocarburos y Consejero del Banco Español de Crédito hasta la intervención de la entidad en 1993. Ha sido profesor de la Universidad Complutense y de la Universidad de Málaga. Pertenece, desde su fundación, al Instituto Español de Analistas Financieros.

En la actualidad es Catedrático de Estructura Económica de la Universidad de Alcalá.

Los últimos libros publicados son:

- La obra de John Maynard Keynes y su visión del mundo financiero (1998, Civitas, Madrid).

- Internacionalización de la Bolsa y de las Finanzas (2000, Pirámide, Madrid).

- La Burbuja Especulativa y la Crisis Económica de Japón (2003, Témpora, Madrid).

- Crisis financieras. Enseñanzas de cinco episodios (2006, Marcial Pons, Madrid).

- Revolución en las Finanzas (Los grandes cambios en las ideas. Represión y Liberalización Financiera) (2008, Marcial Pons, Madrid). 